SALES JÚNIOR, R.; SOARES, S.P.F.; AMARO FILHO, J.; NUNES, G.H.S.; MIRANDA, V.S. Qualidade do melão exportado pelo porto de Natal. Horticultura Brasileira, Brasília, v.22, n.1, p. 98-100, jan-mar 2004.

\title{
Qualidade do melão exportado pelo porto de Natal
}

\author{
Rui Sales Júnior.; Silvana Patrícia F. Soares; Joaquim Amaro Filho; Glauber Henrique S. Nunes; Vicente \\ S. Miranda \\ ESAM, Depto. Fitossanidade, C. Postal 137, 59625-900 Mossoró-RN; E-mail: ruisales@esam.br
}

\section{RESUMO}

Avaliou-se a qualidade pós-colheita dos melões exportados pelo Porto de Natal (RN), identificando características desfavoráveis ao mercado que venham desencadear problemas ao melão exportado. Foram analisados 2.218 frutos de setembro a dezembro de $2001 \mathrm{com}$ amostragem mediante norma de fiscalização da Delegacia da Agricultura e do Abastecimento (DFA/SSV). O trabalho foi desenvolvido no Porto de Natal, na unidade do Vigiagro/SSV/MA. A avaliação dos frutos foi feita de maneira sistemática, seguindo o preenchimento de uma "Ficha de Controle de Qualidade do Melão Exportado" onde foram determinados o teor de sólidos solúveis e a textura ou firmeza de polpa. Concluiu-se que dos frutos analisados $62,58 \%$ destes foram do tipo Amarelo, 15,1\% tipo Orange Flesh, 9,29\% tipo Pele de Sapo, 5,77\% tipo Gália, 5,09\% tipo Cantaloupe e 2,17\% tipo Charentais. Desses, apenas o melão tipo Amarelo apresentou índice médio aceitável de sólidos solúveis para a exportação; o melão tipo Pele de Sapo foi o que apresentou menor índice de firmeza de polpa.

Palavras-chave: Cucumis melo, sólidos solúveis, firmeza de polpa.

\begin{abstract}
Quality of melon exported through the port of Natal, Brazil

We evaluated the post harvest quality of melons exported through the port of Natal, identifying the unfavorable characteristics for the market that could be prejudicial to the exportation. A total of 2.218 fruits was analyzed from September to Dezember 2001. Sampling procedures were done following norms of the Delegacia da Agricultura e do Abastecimento. The work was carried out in the port of Natal. Solid soluble content and fruit firmness were the parameters used to evaluate fruit quality. Nearly $62.58 \%$ of the fruits were of the Yellow type; $15.1 \%$ Orange Flesh type; $9.29 \%$ Piel de Sapo (Frog Skin) type; $5.77 \%$ Gália type; $5.09 \%$ Cantaloupe type and $2.17 \%$ were of the Charentais type. Only the Yellow type melon presented more than $50 \%$ of its fruits with soluble solid content superior to $10^{\circ}$ Brix, and the Frog Skin was the only type with low index for pulp firmness.
\end{abstract}

Keywords: Cucumis melo, solid soluble, pulp firmness.

(Recebido para publicação em 13 de fevereiro de 2003 e aceito em 10 de outubro de 2003)

$\mathrm{E}$ m 2001 exportou-se pelo Porto de Natal (RN) 79 mil toneladas de melão gerando uma renda free on board (FOB) ao redor de US\$29,5 milhões. Atualmente o RN é responsável por $92 \%$ da exportação nacional, sendo estes frutos produzidos nos agropólos MossoróAssú (RN) e Baixo Jaguaribe (CE). A área de produção desta olerícola no Brasil no ano de 2001 foi de aproximadamente 12.000 ha dos quais estimou-se uma produção de 150.000 T (FAO, 2001).

Não obstante, apesar do enorme potencial que a cultura do melão (Cucumis melo L.) apresenta para a balança comercial do estado do Rio Grande do Norte, existem problemas de ordem estrutural e organizacional que exigem soluções urgentes para que haja a garantia de competição no mercado globalizado. Considerando a tendência mundial de incremento das barreiras não tarifárias para proteger a produção interna, os produtores e exportadores bra- sileiros necessitam manter-se atualizados com relação às mudanças das exigências de mercado para desenvolverem ações para reduzir impactos nas exportações.

Uma das características mais estudadas em melão é o teor de sólidos solúveis (SS) (Protade, 1995), fator tradicionalmente utilizado para assegurar sua qualidade. A textura ou firmeza da polpa é outra variável importante na qualidade do fruto, pois indica resistência ao transporte e possibilidade de maior vida de prateleira, estando relacionado com o "flavor", que é perceptível pelo paladar (Menezes et al., 1998).

As condições de cultivo afetam diretamente as características relacionadas com a qualidade dos frutos. Os sólidos solúveis aumentam com a maior salinidade no solo e diminuem com a maior densidade de plantio (Mendlinger, 1994). O momento da colheita é decisivo na concentração de açúcar dos me- lões comercializáveis, não devendo ser menor que $10 \%$ ( $10{ }^{\circ}$ Brix) (Vallespir, 1999). Analisando as exigências do mercado, Souza et al. (1994) verificaram que os melões cultivados para exportação devem ser colhidos com teor de SS entre 9 e $11 \%$ enquanto que para o mercado interno, devem possuir teor de 12 a $14 \%$.

Tendo em vista a importância econômica do melão, tanto para o mercado interno quanto para exportação, investigações devem ser desenvolvidas para aumentar a eficiência do sistema produtivo e a qualidade do produto final. Dessa forma, este trabalho teve por objetivo avaliar a qualidade do melão exportado pelo Porto de Natal.

\section{MATERIAL E MÉTODOS}

A quantidade de melão exportado pelo Porto de Natal, de 11 de setembro a 7 de novembro de 2001 foi de 19,7

1 É a unidade Internacional para expressar a grandeza física força numa superfície de penetração. 
mil toneladas. Nesta, foram analisados 2.218 melões de diferentes tipos (Amarelo, Pele de Sapo, Charentais, Cantaloupe, Orange Flesh e Gália), provenientes do Rio Grande do Norte e do Ceará, conforme o procedimento de rotina do laboratório de Vigilância Agropecuária da DFA/RN (VIGIAGRO) e coletados de 23 empresas exportadoras. Os frutos eram amostrados semanalmente, em um total de duas caixas obtidas aleatoriamente, por embarque/tipo de melão/empresa. Destes foram avaliadas duas variáveis: sólidos solúveis e firmeza de polpa. O valor dos sólidos solúveis foi obtido mediante o uso de refratômetro ótico ATAGO N-1E (0-32\%), avaliando o suco obtido de cada fruto. $\mathrm{O}$ valor da firmeza de polpa foi obtido através de um penetrômetro marca McCormick modelo FT 327 com plunger de ponta cônica de $8 \mathrm{~mm}$ de diâmetro; os resultados obtidos em libras foram convertidos para Newton (N), multiplicando-o pelo fator de conversão 4,45 (Gomes Junior et al., 2001). Em cada fruto era realizado um corte longitudinal, efetuando-se duas leituras eqüidistantes em cada uma das metades equatoriais do fruto.

\section{RESULTADOS E DISCUSSÃO}

No período de realização deste estudo, $62,58 \%$ do melão exportado pelo porto de Natal pertence ao tipo Amarelo. O melão tipo Orange Flesh representou aproximadamente $15,1 \%$ das exportações e o tipo Pele de Sapo 9,29\%. Os demais tipos Galia, Cantaloupe e Charentais apresentaram apenas 5,77\%; $5,09 \%$ e 2,17\%, respectivamente (Figura 1). O volume de melão exportado neste período foi de $19.696,930 \mathrm{~kg}$ e a amostragem representou $0,02 \%$ deste volume.

Observou-se que o melão tipo Amarelo foi aquele que apresentou o maior percentual de frutos $(52,0 \%)$, com valores de SS acima do mínimo exigido ( $10^{\circ}$ Brix). Ao contrario, o melão tipo Charentais apresentou $100,0 \%$ dos frutos analisados com valor de SS inferior ao mínimo aceitável pelo mercado internacional $\left(13^{\circ} \mathrm{Brix}\right)$ (Alves et al. 2000). Os demais tipos de frutos, Galia,

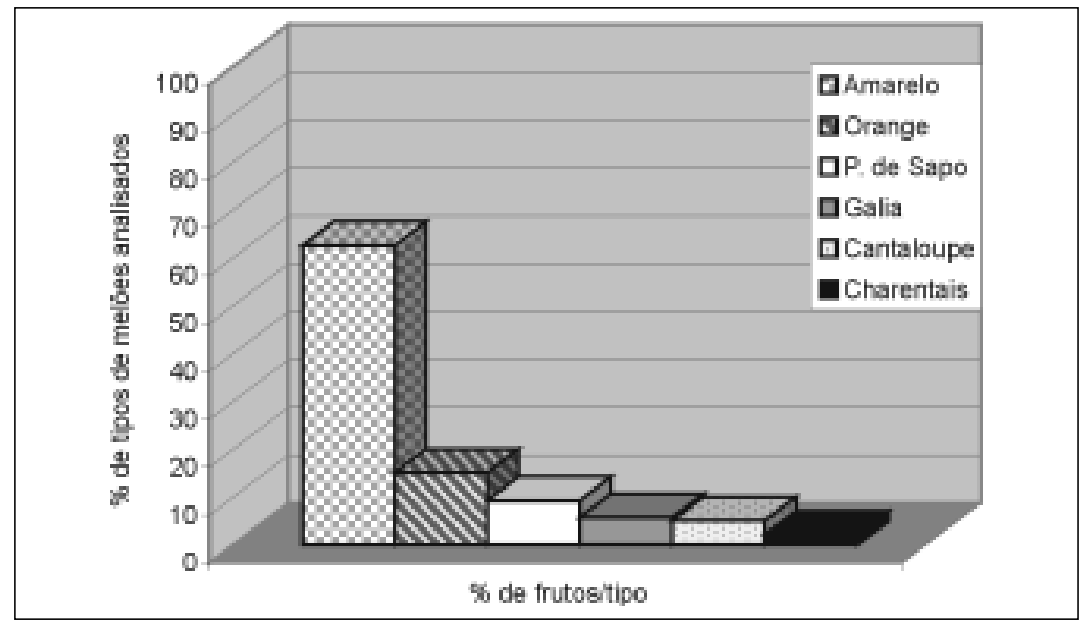

Figura 1. Tipos de melões (\%) exportados pelo Porto de Natal de 11 de setembro a 7 de novembro de 2001. Mossoró, ESAM, 2001.

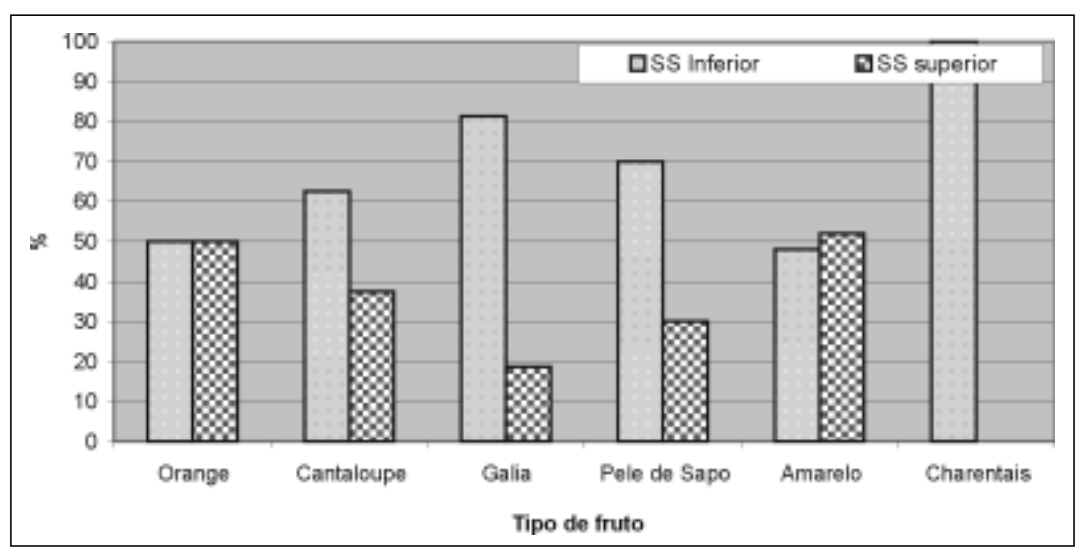

Figura 2. Sólidos solúveis (SS) médios dos frutos exportados pelo Porto de Natal, de 11 de setembro a 7 de novembro de 2001. Mossoró, ESAM, 2001.

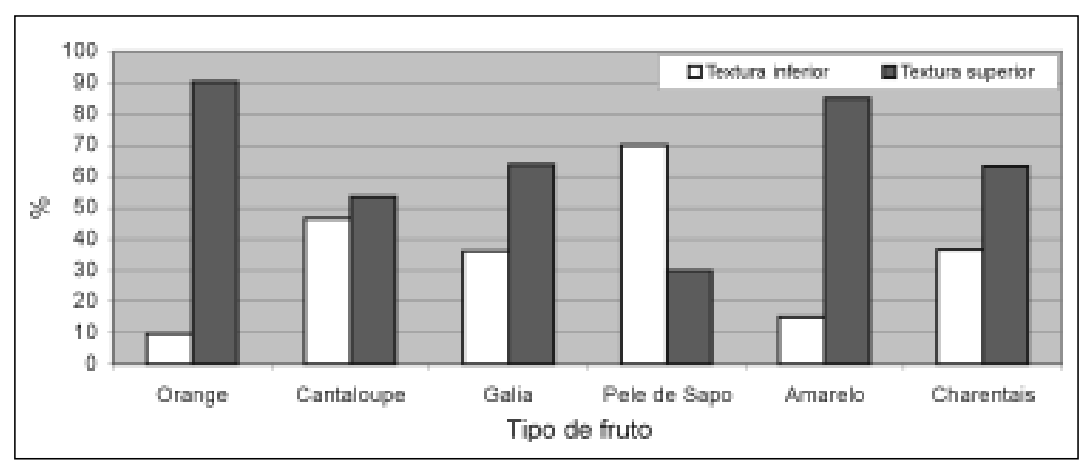

Figura 3. Textura média dos frutos exportados pelo Porto de Natal, de 11 de setembro a $7 \mathrm{de}$ novembro de 2001. Mossoró, ESAM, 2001.

Pele de Sapo, Cantaloupe e Orange Flesh apresentaram 81,35\%; 70,00\%; $62,62 \%$ e $50,00 \%$ respectivamente, de $\mathrm{SS}$ inferior ao mínimo exigido pelo mercado internacional: $12,11,10 \mathrm{e}$ $10^{\circ}$ Brix, respectivamente, segundo Alves et al. 2000 (Figura 2). O índice de maturidade dos frutos apresenta-se de forma diferente para cada tipo e em alguns casos por variedade. Segundo 
Alvarado (1994) e Gomes Jr. et al. (2001) em melões das variedades Reticulatus e Cantaloupensis o melhor indicativo para colheita é o grau de separação entre o fruto e o pedúnculo; no caso da separação completa, o fruto está com o máximo desenvolvimento das condições organolépticas (SS, firmeza de polpa e aroma). No caso de melões da variedade Inodorus, obtém-se o índice de colheita pela análise dos SS, implicando na destruição do fruto e, consequentemente não havendo um indicativo do ponto de colheita. Giambanco de Ena (1997a) recomenda os índices de 12 a $14^{\circ}$ Brix para os meIões tipo Amarelo e Gália, sendo o valor de SS para o melão tipo Amarelo superior ao recomendado por Alves et al. (2000). É possível que os valores atribuídos por Giambanco de Ena (1997b) sejam atribuídos para o mercado interno espanhol ou para mercados de curta distância. No caso do melão brasileiro que necessita pelo menos 15-20 dias para estar na mesa do consumidor europeu, este valor deve estar ao redor de $10^{\circ} \mathrm{Brix}$ pois o estágio de maturação é inversamente proporcional ao tempo de conservação pós-colheita (Mutton et al., 1981; Welles e Buitelaar, 1988). Para melões tipo Pele de Sapo e Cantaloupe, Giambanco de Ena (1997a) recomendam valores superiores a 12 e $10^{\circ}$ Brix, respectivamente, sendo esses valores bastante superiores no caso do melão tipo Charentais (13 a $15^{\circ}$ Brix).
O melão tipo Orange Flesh apresentou o maior percentual de frutos com firmeza superior ao mínimo exigido (90,33\%), seguido dos melões tipo Amarelo (85,00\%), Gália (63,89\%), Charentais $(63,33 \%)$ e Cantaloupe $(53,45 \%)$, sendo os valores mínimos exigidos de 30, 24, 30 e $35 \mathrm{~N}$, respectivamente. O melão tipo Pele de Sapo apresentou o maior percentual de frutos com valor de firmeza inferior ao mínimo exigido (70,00\%), que segundo Alves et al. (2000) é de $32 \mathrm{~N}^{1}$ (Figura 3).

Vale ressaltar que este é o primeiro trabalho realizado com dados de qualidade de todas as empresas (23 no total) exportadoras de melão do Rio Grande do Norte e Ceará.

\section{LITERATURA CITADA}

ALVARADO, P. Factores de producción y manejo de poscosecha determinantes en la calidad de melones. EN: Curso Internacional "Calidad de frutas y hortalizas frescas de exportación para el mercado europeu. Normativa de la CE". Fundación Chile, Dpto. Agroindustrial Santiago, 17 a 19 de mayo de 1994: 16/1-16/12. 1994.

ALVES, R.E.; PIMENTEL, C.R.; MAIA, C.E.; CASTRO, E.B.; VIANA, F.M.; COSTA, F.V.; ANDRADE, G.G.; FILGUEIRAS, H.A.C.; ALMEIDA, J.H.S.; MENEZES, J.B.; COSTA, J.G.; PEREIRA, L.S.E. Manual de melão para exportação. Embrapa. Brasília, DF, 2000. 51 p. FAO. Dados Agrícolas de FAOSTAT - Producción - cultivo y ganado primarios y derivados. Disponível em <www.url:http:// apps.fao.org>. Acesso em 07/04/03.
GOMES JÚNIOR, J.; MENEZES, J.B.; NUNES, G.H.S.; COSTA, F.B.; SOUZA, P.A. Qualidade pós-colheita do melão tipo Cantaloupe, colhido em dois estádios de maturação. Horticultura Brasileira, Brasília, v.19, n.3, p.356-360, 2001.

GIAMBANCO DE ENA, H. Manejo poscosecha del melón. En: Melones. Coord. A. Namesny. Ediciones de Horticultura, reus. 277 p: p.165-174, 1997a.

GIAMBANCO DE ENA, H. Comercialización del melón. En: Melones. Coord.. A. Namesny. Ediciones de Horticultura, Reus. 277 p: p.175-178, 1997b.

MENDELINGER, S. Effect of increasing plant density and salinity on yield and fruit quality in muskmelon. Scientia Horticulturae, v.57, p.41-49, 1994.

MENEZES, J.B.; CASTRO, E.B.; PRAÇA. E.F.; GRANGEIRO, L.C.; COSTA, L.B.A. Efeito do tempo de insolação pós-colheita sobre a qualidade do melão amarelo. Horticultura Brasileira, Brasília, v.16, n.1, p.80-81, 1998.

MUTTON, L.L.; CULLIS, B.R.; BLAKENEY, A.B. The objective definition of quality in rockmelons (Cucumis melo L.). Journal Science Food Agricultural, v.32, p.385-391, 1981.

PROTRADE. Melons - Export Manual: Tropical fruits and vegetables. Eschborn: GTZ, 1995, 36 p. SOUZA, M.C.; MENEZES, J.B.; ALVES, R.E. Tecnologia Pós-Colheita e Produção de Melão no Estado do Rio Grande do Norte. Horticultura brasileira, Brasília, v.12, n.2, p.188-190,1994.

VALLESPIR, A.N. Post-Recolección de Hortalizas. Compendio de Horticultura, Volume III, 1999, $301 \mathrm{p}$.

WELLES, G.W.H.; BUITELAAR, K. Factors soluble solids content of muskmelon (Cucumis melo L.). Netherlands Journal of Agricultural Science, v.36, p.239-246, 1988. 